\title{
Assessment of Flexural Strength and Cytotoxicity of Heat Cure Denture Base Resin Modified with Titanium Dioxide Nanoparticles: An In Vitro Study
}

\author{
Varun Raj ${ }^{1}$, Vinaya Bhat ${ }^{2}$, Nivya John ${ }^{3}$, Athma Shetty ${ }^{4}$, Suja Joseph ${ }^{5}$, Rene Kuriakose ${ }^{6}$, Shifas Hameed ${ }^{7}$
}

\begin{abstract}
Aims: To assess the effect of titanium dioxide nanoparticles (NPs) on flexural strength and cytotoxicity of heat-cured polymethyl methacrylate (PMMA) resins.

Methodology: Sixty-four rectangular and 12 circular specimens were fabricated from metal dies to test flexural strength and cytotoxicity, respectively. The rectangular specimens were grouped into four (16 specimens each)—control group (Group 1), Group 2 with $3 \%$ TiO ${ }_{2}$, Group 3 with $5 \% \mathrm{TiO}_{2}$, and Group 4 with $7 \% \mathrm{TiO}_{2}$. They were tested for flexural strength using universal testing machine. The circular specimens were grouped into two (six specimens each)—control group and the test group which included the group which showed a highest flexural strength. They were tested for cytotoxicity using MTT assay. The analysis of variance (ANOVA) test was used to analyze the mean flexural strength of each group and Tukey's post hoc test, for pairwise group comparison $(p<0.05)$. An independent sample $t$-test was used to analyze the cytotoxicity between the groups $(p<0.05)$.

Result: The study showed that there was a significant decrease in the flexural strength from the control group (mean: 298.95), which reduced as the concentration of $\mathrm{TiO}_{2}$ increased. However, the toxicity reduced considerably from 24 hours to 7 days in both groups while the test group showed better cell viability (\%) than the control group.

Conclusion: The flexural strength of heat cure acrylic resin (modified and unmodified) was much higher than the recommended flexural strength for these resins. On adding $\mathrm{TiO}_{2} \mathrm{NPs}$, flexural strength decreased when compared to the control group. However, with $3 \% \mathrm{TiO}_{2} \mathrm{NPs}_{\text {, there was }}$ no significant decrease in flexural strength as compared to conventional resins. $\mathrm{TiO}_{2} \mathrm{NP}$-modified heat cure acrylic resin showed less toxicity on day 1 and even lesser toxicity after 7 days indicating that it is biocompatible.

Clinical significance: $\mathrm{TiO}_{2} \mathrm{NPs}$ incorporated at $3 \%$ concentration in denture base resin had less cytotoxicity and adequate flexural strength, to be used as a promising alternative to conventional denture base resin.

Keywords: Biocompatibility, Cytotoxicity, Denture base resin, Flexural strength, Polymethyl methacrylate, Titanium dioxide

The Journal of Contemporary Dental Practice (2021): 10.5005/jp-journals-10024-3157
\end{abstract}

\section{INTRODUCTION}

Since 1937, the most frequently used material for fabrication of dentures is polymethyl methacrylate (PMMA) resin, as it shows good physical, esthetic, and mechanical properties. However, the dentures made with these materials are highly vulnerable to microbial adhesion. This is mainly because they are susceptible to plaque accumulation due to their food-retentive properties and surface porosities. The opportunistic fungi of the oral cavity Candida albicans (C. albicans) act upon these and form denture stomatitis of the palatal mucosa. It has been reported that mechanical cleansing alone cannot reduce microbial adhesion on denture bases; hence, researchers started working on the concept of adding antimicrobial agents into the denture base materials. Since then, antimicrobial activities of dental materials have been improved by the addition of some nanoparticles (NPs) like titanium dioxide $\left(\mathrm{TiO}_{2}\right)$, silicone dioxide $\left(\mathrm{SiO}_{2}\right)$, and zinc dioxide $\left(\mathrm{ZnO}_{2}\right)$. Among them, $\mathrm{TiO}_{2}$ has received recent attention due to its prominent catalytic effect, low toxicity, high stability, white color, efficiency, low cost, and availability. ${ }^{1}$ Nanoparticles when incorporated are known to alter the mechanical properties of denture materials. According to the International Standard for denture base polymers, the minimal limit for flexural strength of any polymerized material should not be less than $65 \mathrm{MPa}^{2}{ }^{2}$ Hence, it is advisable to evaluate the effects of these NPs on the mechanical properties of the acrylic materials
${ }^{1,5,6}$ Department of Prosthodontics and Crown and Bridge, Pushpagiri College of Dental Sciences, Pathanamthitta, Kerala, India

${ }^{2-4}$ Department of Prosthodontics and Crown and Bridge, AB Shetty Memorial Institute of Dental Sciences, NITTE (Deemed to be University), Mangaluru, Karnataka, India

${ }^{7}$ Department of Prosthodontics and Crown and Bridge, PSM Dental College, Thrissur, Kerala, India

Corresponding Author: Nivya John, Department of Prosthodontics and Crown and Bridge, AB Shetty Memorial Institute of Dental Sciences, NITTE (Deemed to be University), Mangaluru, Karnataka, India, e-mail: nivyajohn@nitte.edu.in

How to cite this article: Raj V, Bhat V, John N, et al. Assessment of Flexural Strength and Cytotoxicity of Heat Cure Denture Base Resin Modified with Titanium Dioxide Nanoparticles: An In Vitro Study. J Contemp Dent Pract 2021;22(9):1025-1029.

Source of support: Nil

Conflict of interest: None

whether they reduce their flexural strength below the standard level. In addition to this due to specific chemical and structural properties of NPs, their incorporation into acrylic resin may cause additional health hazards. Biocompatibility of a dental material is of major concern, as the prosthesis would be worn for a long 
time. Although there was a study done by Hardita et al. $^{3}$ on the biocompatibility of the denture base acrylic resin modified with $\mathrm{TiO}_{2} \mathrm{NPs}$, there is no study analyzing the strength of the material in different concentrations.

Hence, the present study was taken up with the aims, of assessing the influence of different concentrations of $\mathrm{TiO}_{2} \mathrm{NPs}$ incorporated into the heat-cured PMMA resins on the flexural strength and to assess the cytotoxicity of the denture base resin modified with titanium dioxide $\mathrm{NPs}\left(\mathrm{TiO}_{2} \mathrm{NP}\right)$.

\section{Materials and Methodology}

The study was conducted at AB Shetty Memorial Institute of Dental Sciences. Institutional ethical clearance certificate was obtained.

\section{Fabrication of Test Specimens}

Six rectangular dies of dimension $31 \times 11 \times 3 \mathrm{~mm}$ (Fig. 1A) were fabricated in metal. The acrylic specimens fabricated from this die were used to study flexural strength.

\section{Preparation of Test Materials}

\section{Proportioning}

A total of 64 acrylic specimens were fabricated from the abovementioned metal dies. They were divided into four groups-a control group containing the 16 conventional acrylic resins (Group 1), a group of 16 conventional acrylic resins modified with $3 \% \mathrm{TiO}_{2}$ (Group 2), a group of 16 conventional acrylic resins modified with $5 \% \mathrm{TiO}_{2}$ (Group 3), and a group of 16 conventional acrylic resins modified with $7 \% \mathrm{TiO}_{2}$ (Group 4).

\section{Mixing of $3 \% \mathrm{TiO}_{2}$ in Denture Base Resin}

$24 \mathrm{~g}$ of Polymer and $9.38 \mathrm{~g} \mathrm{(10} \mathrm{mL)} \mathrm{monomer} \mathrm{is} \mathrm{mixed} \mathrm{to} \mathrm{make}$ the total weight of the mixture $33.38 \mathrm{~g}(34 \mathrm{~g})$ i.e., $3 \%$ of the mass. Similarly $5 \%$ and $7 \% \mathrm{TiO}_{2}$ were proportioned and mixed using mortar and pestle.

\section{Acrylization}

The metal dies were used to acrylize the abovementioned denture base resins in the conventional method of flasking and acrylizing in dental flask. The final specimens were trimmed and polished to get a rectangular specimen of dimensions $30 \times 10 \times 2 \mathrm{~mm}$ and circular specimen of $5 \times 2 \mathrm{~mm}$ dimensions.

\section{Cytotoxicity}

Only the group which showed a highest flexural strength was considered. For this study, 12 circular specimens were fabricated (Fig. 1B),i.e., 6 modified with $\mathrm{TiO}_{2} \mathrm{NPs}$ and 6 without any modification (control group). They were also subjected to aging process in distilled water. These groups were tested at 1-day and 7-day intervals for cytotoxicity.

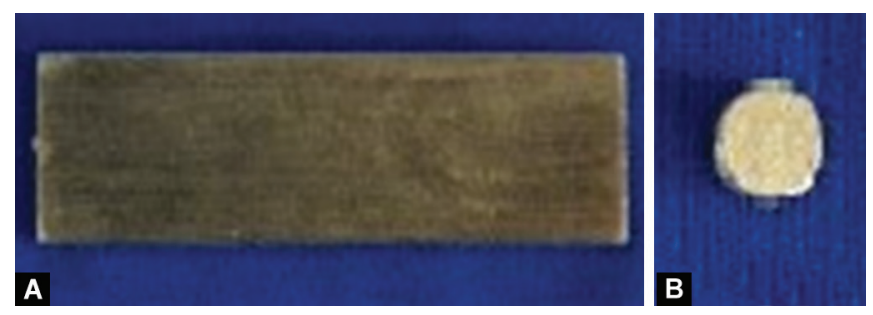

Figs 1 A and B: (A) Rectangular, and (B) Circular metal die used in the study

\section{Study of Various Properties}

\section{Flexural Strength}

The specimens were placed on the universal testing machine for three-point bending test at a crosshead speed of $5 \mathrm{~mm} /$ minute. Load was applied using a centrally located rod until fracture had occurred. The load applied at the time of fracture was noted. The flexural strength of the specimens was calculated using the standard equation: ${ }^{4} S=3 L P / 2 W T^{2}$ where $S$-flexural strength, $P$ - maximum load before fracture, $L-$ distance between supports, $W$-width of the specimen, and $T$ - thickness of the specimen.

\section{Cytotoxicity Assessment}

This experiment was performed at the NITTE University Centre for Science Education and Research (NUCSER), KSHEMA, NITTE University. Human gingival fibroblasts were isolated and utilized from the laboratory. The toxicity of the specimens was determined using MTT [3-(4,5 dimethylthiazol-2-yl)2,5-diphenyltetrazolium bromide] assay on human gingival fibroblasts to determine the percentage of viable cells in the culture media. In brief, cells were seeded in well plates and incubated for 24 hours at $37^{\circ} \mathrm{C}$ in a humidified atmosphere of $5 \% \mathrm{CO}_{2}$ and $95 \%$ air. After that, the cell culture medium was discarded and specimen extracts were added. After 24-hour incubation period in $5 \% \mathrm{CO}_{2}$ environment, the supernatant was removed and MTT solution was added to the medium in each well and the plates were incubated for 4 hours at $37^{\circ} \mathrm{C}$ and $5 \%$ $\mathrm{CO}_{2}$. Then, the medium with MTT was removed and dimethyl sulfoxide (DMSO) solution was added to each well to dissolve the formazan crystals. Then, the optical density (absorbance value) at $570 \mathrm{~nm}$ was recorded using an ELISA plate reader and the cell viability was also calculated.

\section{Statistical Analysis}

In this study, the data were statistically analyzed using the SPSS version 22 (IBM) software. The ANOVA test was used to analyze the mean flexural strength of each group followed by Tukey's post hoc test, which was used for pairwise comparison of the flexural strength between the groups ( $p<0.05$ ). The independent sample $t$-test was used to analyze the cytotoxicity between the groups after 24 hours and after 7 days. Paired $t$-test was used to analyze the cytotoxicity within the groups after 24 hours and after 7 days $(p<0.05)$.

\section{Results}

\section{Flexural Strength}

The values obtained were statistically analyzed. There was a significant decrease in the flexural strength in the comparison of the control group (Group 1) and Group 4. The highest flexural strength was seen in the control group (mean: 298.95), which reduced as the concentration of $\mathrm{TiO}_{2}$ increased. The least flexural strength was seen in Group 4 (mean: 202.74). The flexural strength of Group 2 and Group 3 was 280.96 and $227.30 \mathrm{MPa}$, respectively (Tables 1 and 2, Fig. 2).

\section{Cytotoxicity}

Since the resin modified with $3 \% \mathrm{TiO}_{2}$ showed almost equivalent flexural strength to control group, cytotoxicity study was conducted using this as test group. Twelve circular acrylic disks were fabricated 
Table 1: Comparison of flexural strength between the study groups

\begin{tabular}{lccccccc}
\hline & & & & & & \multicolumn{2}{c}{ ANOVA } \\
\cline { 6 - 8 } & $N$ & Mean & SD & Minimum & Maximum & $F$ & pvalue \\
\hline Control (Group 1) & 16 & 298.95 & 20.24 & 252.90 & 333.40 & & \\
Group 2 & 16 & 280.96 & 28.21 & 223.80 & 333.40 & & \\
Group 3 & 16 & 227.30 & 31.79 & 174.00 & 288.00 & 45.686 & $<0.001^{*}$ \\
Group 4 & 16 & 202.74 & 24.93 & 161.80 & 244.20 & & \\
\hline
\end{tabular}

${ }^{*} p<0.05$ statistically significant; $p>0.05$ nonsignificant, NS. This table reveals that there is a significant decrease in the flexural strength from the control to Group 4

Table 2: Pairwise comparison of flexural strength between the study groups (Tukey's post hoc test)

\begin{tabular}{llccccc}
\hline & & Mean difference & & & \multicolumn{2}{c}{ 95\% confidence interval } \\
\cline { 5 - 7 } (I) group & $(J)$ group & $(I-J)$ & Std. error & $p$ value & Lower bound & Upper bound \\
\hline Control & Group 1 & 17.99 & 9.42 & $0.24(\mathrm{NS})$ & -6.90 & 42.88 \\
& Group 2 & 71.65 & 9.42 & $<0.001^{*}$ & 46.76 & 96.54 \\
& Group 3 & 96.21 & 9.42 & $<0.001^{*}$ & 71.32 & 121.09 \\
Group 1 & Group 2 & 53.66 & 9.42 & $<0.001^{*}$ & 28.78 & 78.55 \\
& Group 3 & 78.22 & 9.42 & $<0.001^{*}$ & 53.33 & 103.11 \\
Group 2 & Group 3 & 24.56 & 9.42 & $0.054(\mathrm{NS})$ & -0.33 & 49.44 \\
\hline
\end{tabular}

${ }^{*} p<0.05$ statistically significant; $p>0.05$ nonsignificant, NS

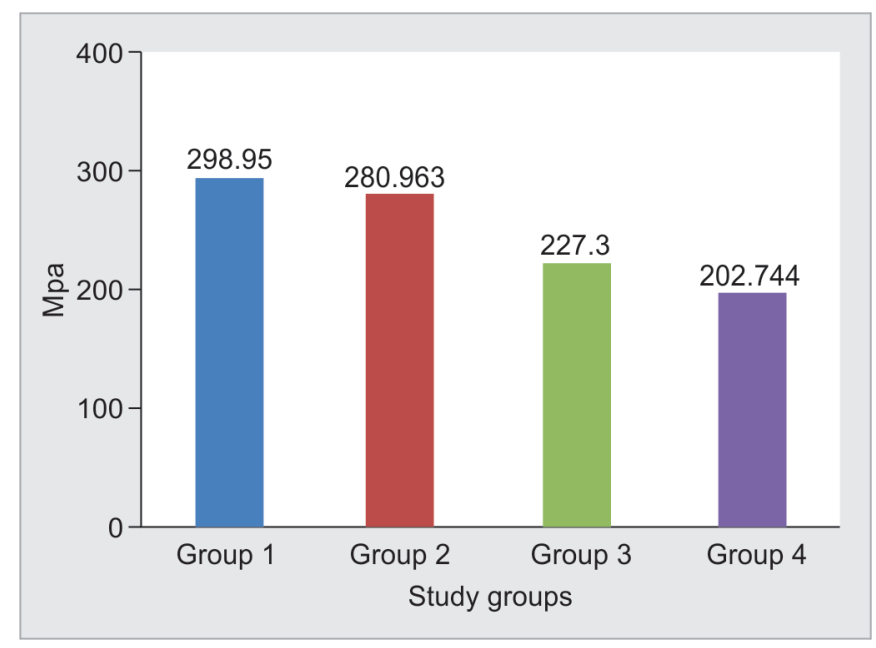

Fig. 2: Mean flexural strength of all groups

and divided into two groups-a control group and $3 \% \mathrm{TiO}_{2}-$ modified group. All the specimens were tested for cytotoxicity using MTT assay. The cell viability for each specimen was calculated and tabulated (Tables 3 and 4).

Figure 3 shows that the toxicity reduced considerably from 24 hours to 7 days in both the groups (i.e., control group and 3\% $\mathrm{TiO}_{2}$-modified group). The test group shows better cell viability (\%) than the control group on both occasions. This shows that the addition of $\mathrm{TiO}_{2}$ NPs renders the PMMA more biocompatible.

\section{Discussion}

Fabrication of dentures is commonly performed with the help of heat cure PMMA resin. This is because PMMA shows adequate

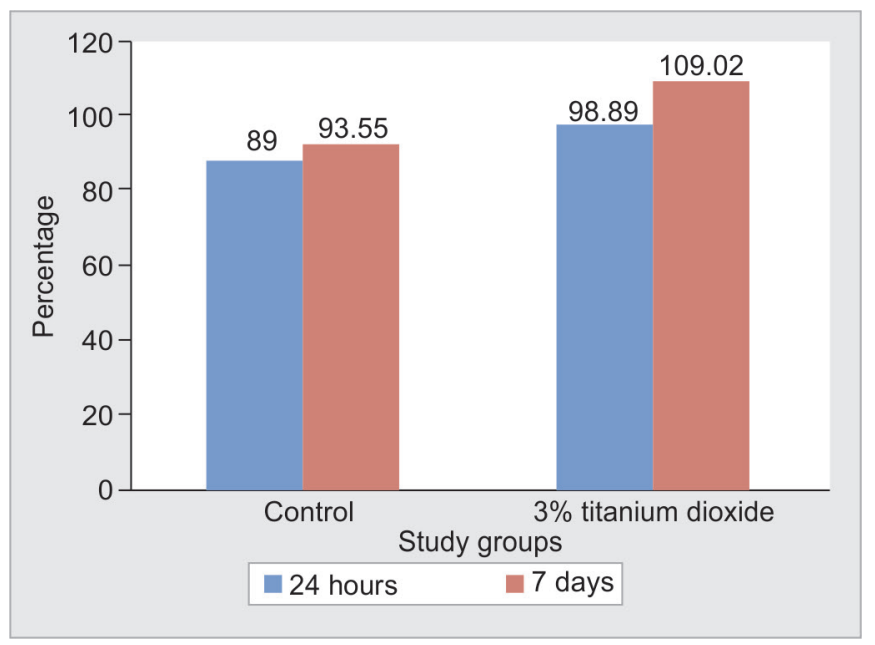

Fig. 3: Comparison of cytotoxicity between the study groups

dimensional stability, easy availability, good compatibility with oral tissues, easy handling characteristics, and adequate color. But one of the main problems faced by dentists and patients is its vulnerability to microbial adhesion. When compared to natural tooth surface, microorganisms display more adherence to acrylic resin. ${ }^{1}$ Hence, attempts to incorporate specific antimicrobial agents into the denture resin has been made. Of the various antimicrobial agents used, NPs have gained great attention, as it is easily available and very effective. ${ }^{5}$ The nanoparticles are usually available in a size less than $100 \mathrm{~nm}$, and they have been used for their features to fight infection. The reason for this could be their increased ratio of surface area to volume. Due of their antiadhesive and biocidal properties, the NPs thus have the property to inhibit biofilm formation in the oral cavity. Because of this, their possible use as components of 
Finding Flexural Strength and Cytotoxicity with Titanium Dioxide Nanoparticles

Table 3: Comparison of cytotoxicity between the study groups

\begin{tabular}{|c|c|c|c|c|c|c|c|c|c|}
\hline & & Group & $N$ & Mean & $S D$ & Mean difference $(95 \% \mathrm{Cl})$ & $t$ & $d f$ & $p$ value \\
\hline \multirow[t]{2}{*}{24 hours } & \multirow{2}{*}{$\begin{array}{c}\text { Percentage } \\
\text { viability }\end{array}$} & 1 & 3 & 89.00 & 2.23 & \multirow[t]{2}{*}{$-4.56(-8.37,-0.75)$} & \multirow[t]{2}{*}{-3.32} & \multirow[t]{2}{*}{4} & \multirow[t]{2}{*}{$0.03^{*}$} \\
\hline & & 2 & 3 & 93.55 & 0.81 & & & & \\
\hline \multirow[t]{2}{*}{7 days } & \multirow{2}{*}{$\begin{array}{c}\text { Percentage } \\
\text { viability }\end{array}$} & 1 & 3 & 98.89 & 2.61 & \multirow[t]{2}{*}{$-10.12(-16.03,-4.22)$} & \multirow[t]{2}{*}{-4.76} & \multirow[t]{2}{*}{4} & \multirow[t]{2}{*}{$0.009^{*}$} \\
\hline & & 2 & 3 & 109.02 & 2.59 & & & & \\
\hline
\end{tabular}

${ }^{*} p<0.05$ statistically significant; $p>0.05$ nonsignificant, NS

Table 4: Comparison of cytotoxicity between the time intervals in each study group

\begin{tabular}{|c|c|c|c|c|c|c|c|c|c|}
\hline \multicolumn{3}{|c|}{ Group } & \multirow{2}{*}{$\frac{N}{3}$} & \multirow{2}{*}{$\begin{array}{r}\text { Mean } \\
89.00\end{array}$} & \multirow{2}{*}{$\frac{S D}{2.23}$} & \multirow{2}{*}{$\frac{\text { Mean difference }(95 \% \mathrm{Cl})}{-9.90(-11.13,-8.66)}$} & \multirow{2}{*}{$\frac{T}{-34.44}$} & \multirow{2}{*}{$\frac{d f}{2}$} & \multirow{2}{*}{$\frac{p \text { value }}{0.001^{*}}$} \\
\hline 1 & Percentage viability & 24 hours & & & & & & & \\
\hline & & 7 days & 3 & 98.89 & 2.61 & & & & \\
\hline \multirow[t]{2}{*}{2} & Percentage viability & 24 hours & 3 & 93.55 & 0.81 & $-15.46(-20.78,-10.15)$ & -12.51 & 2 & $0.006^{*}$ \\
\hline & & 7 days & 3 & 109.02 & 2.59 & & & & \\
\hline
\end{tabular}

${ }^{*} p<0.05$ statistically significant; $p>0.05$ nonsignificant, NS

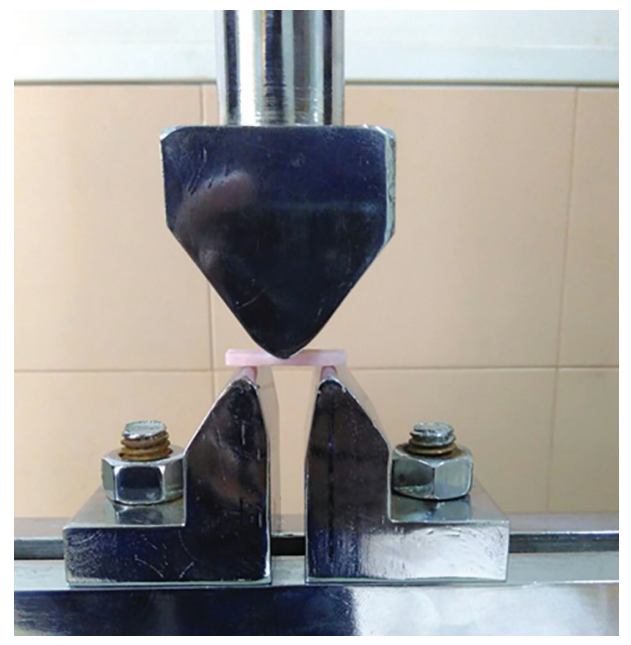

Fig. 4: Load testing on the rectangular acrylic specimen on a universal testing machine

coatings for prosthetic devices either local application or altering the intrinsic property with their incorporation has been explored. ${ }^{1}$ Recently, among them, $\mathrm{TiO}_{2}$ has attained more importance because of its better properties such as high stability, greater photocatalytic activity, low cost, and human and environmental safety. ${ }^{4}$ The

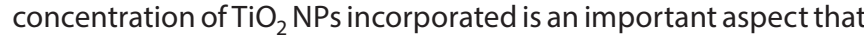
influences the mechanical properties of the modified acrylic. This has been confirmed by studies conducted by various authors. 2,5,6

In the present study, $\mathrm{TiO}_{2}$ was commercially obtained and PMMA specimens were fabricated with 3,5 , and $7 \%$ concentration of $21 \mathrm{~nm} \mathrm{TiO}{ }_{2}$ added to the polymer. Rectangular specimens were fabricated for accommodating the universal testing machine for flexural strength. Circular specimens were fabricated for studying cytotoxicity effects of $\mathrm{TiO}_{2}$. For the abovementioned tests, equal numbers of control group specimens were included. The rectangular specimens were subjected to three-point bending test in a universal testing machine (Fig. 4).

The results showed that there was a significant decrease in the flexural strength from the control group, which showed the highest mean flexural strength (298.95 MPa), to the group containing $7 \%$ $\mathrm{TiO}_{2}$-modified acrylic resin (202.74 MPa), which showed the least mean flexural strength (Table 1).

The concentration of $\mathrm{TiO}_{2}$ was inversely proportional to the flexural strength of acrylic resin, which means that when the concentration of $\mathrm{TiO}_{2}$ was increased, there was a decrease in the flexural strength of acrylic resin. Though there was a decrease in the flexural strength of the specimens, it was noted that all the groups showed flexural strength more than the minimum requirement of flexural strength for acrylic resin according to the ADA specification no. 12, i.e., $65 \mathrm{MPa}$. Nazirkar et al. in their study concluded that $\mathrm{TiO}_{2} \mathrm{NP}$ incorporation into acrylic resin can adversely affect the flexural strength of the final product and is directly proportional to the concentration of NP. Sodagar et al. also evidenced a drop in flexural strength in their study. ${ }^{2}$ Elsaka et al. observed that with $3 \%$ $(\mathrm{w} / \mathrm{w}) \mathrm{TiO}_{2} \mathrm{NP}$ incorporation in glass ionomer cement, mechanical flexural strength improved. ${ }^{7}$ Ahmed et al. also in their study found that the $\mathrm{TiO}_{2} \mathrm{NP}$ incorporation had an adverse effect on the flexural strength of conventional heat polymerized acrylic resin. ${ }^{8,9}$ In contrast, flexural properties changed as per the concentrations of $\mathrm{TiO}_{2} \mathrm{NPs}$ added to PMMA than those of normal PMMA and showed improved results in studies done by several studies. ${ }^{10-15}$

Nevertheless, in our study $3 \%$ addition of $\mathrm{TiO}_{2} \mathrm{NPs}$ gave equivalent results as the control group $(p>0.05)$. The statistical analysis showed that there was no significant difference between the mean flexural strength of the control group and Group 2 with $3 \% \mathrm{TiO}_{2}$-modified acrylic resin $(280.96 \mathrm{MPa})(p>0.05)$ (Table 2$)$. This could mean that adding $3 \% \mathrm{TiO}_{2}$ to the acrylic resin would not reduce the flexural strength. There was a significant reduction in the flexural strength in Groups $3(227.3 \mathrm{MPa})$ and 4 when compared to control group and Group $2(p<0.05)$, whereas there was no significant difference between Groups 3 and 4 ( $p>0.05$ ).

The flexural strength values may be decreased due to the nanosized oxides present in the intrinsic molecular structure of the polymerized PMMA. TiO 2 NPs might present as an impurity and interfere with the polymerization reaction, thereby functioning as a plasticizer. This in turn can increase in the amount of residual unreacted monomer, which is considered to cause the decrease in the strength of the material. Incorporated NPs can also cause the particles to aggregate and agglomerate, further creating a stress 
concentrating center that can lead to unfavorable mechanical properties. ${ }^{7}$ The denture base resin contacts not only the wearer's oral mucosa, but also the skin of the dentist and dental technician, so a guarantee of high safety has to be established prior to clinical use. Hence, the tests for cytotoxicity of the specimens were carried out using MTT assay on human gingival fibroblasts. Results showed that the test group $\left(3 \% \mathrm{TiO}_{2}\right)$ showed higher cell viability than the control group in both occasions ( 24 hours and 7 days) (Table 3 ).

The results showed that both control and $\mathrm{TiO}_{2}$-modified acrylic resin were not toxic and the test group proved to be less toxic than the control group on both occasions, i.e., after 24 hours and 7 days. After 7 days, in distilled water, the level of toxicity was reduced for both the groups (Table 4). The result of the present study is in accordance with other studies. ${ }^{4,16}$ Aging resulted in a significant decrease in cytotoxicity in both groups may be due to the release of unbound molecules into the aqueous media. In a study carried out by Tsuji et al., ${ }^{17}$ they evaluated the biocompatibility of $\mathrm{TiO}_{2}$ coated acrylic resin. They concluded from the study that $\mathrm{TiO}_{2}$ did not cause any sensitive reactions or irritation to oral mucosa, and hence, it is biocompatible with the oral mucosa.

Heravi et al. ${ }^{16}$ conducted a cytotoxicity (in vitro) assessment of $\mathrm{TiO}_{2}$-modified orthodontic composite resin. They concluded that $\mathrm{TiO}_{2}$-modified orthodontic composite showed comparable or even less cytotoxicity than its unmodified counterpart, which means that it does not show any additional health hazards compared to conventional composite resin.

\section{LiMITATIONS}

Further studies have to be done by mixing the $\mathrm{TiO}_{2}$ in the monomer to ensure a homogeneous mix. Antifungal activity, especially $C$. albicans also, can be analyzed and the size of $\mathrm{TiO}_{2}$ used should be in between 1 and $10 \mathrm{~nm}^{1}$ as they show their highest antifungal activity in this size range.

\section{Conclusion}

Within the limitations of this study, it may be concluded that the flexural strength of heat cure acrylic resin (modified and unmodified) was much higher than the recommended flexural strength for these resins. On adding $\mathrm{TiO}_{2} \mathrm{NPs}$, flexural strength was decreased when compared to the control group. However, with $3 \% \mathrm{TiO}_{2} \mathrm{NPs}$, there was no significant decrease in flexural strength as compared to conventional resins. $\mathrm{TiO}_{2} \mathrm{NP}$-modified heat cure acrylic resin showed less toxicity on day 1 and even lesser toxicity after 7 days indicating that it is biocompatible.

\section{References}

1. Nazirkar G, Bhanushali S, Singh S, et al. Effect of anatase titanium dioxide nanoparticles on the flexural strength of heat cured poly methyl methacrylate resins: an in-vitro study. J Indian Prosthodont Soc 2014;14(Suppl. 1):144-149. DOI: 10.1007/s13191-014-0385-8.
2. Sodagar A, Bahador A, Khalil S, et al. The effect of $\mathrm{TiO}_{2}$ and $\mathrm{SiO}_{2}$ nanoparticles on flexural strength of poly (methyl methacrylate) acrylic resins. J Prosthodont Res 2013;57(1):15-19. DOI: 10.1016/j. jpor.2012.05.001.

3. Hardita A, Ismiyati T, Wahyuningtyas E. Effect of addition titanium dioxide nanoparticles as acrylic resin denture base filler on cytotoxicity. Majalah Kedokteran Gigi Indonesia 2019;5(2):86-91. DOI: 10.22146/majkedgiind.38438.

4. Sadhvi K, Jayakar S, Chandrasekharan K. Effect of disinfectants on modified denture base resins. LAP Lambert Academic Publishing; 2013.

5. Arai $T$, Ueda $T$, Sugiyama $T$, et al. Inhibiting microbial adhesion to denture base acrylic resin by titanium dioxide coating. J Oral Rehabil 2009;36(12):902-908. DOI: 10.1111/j.1365-2842.2009.02012.x.

6. Sivakumar I, Arunachalam KS, Sajjan S, et al. Incorporation of antimicrobial macromolecules in acrylic denture base resins: a research composition and update. J Prosthodont 2014;23(4):284-290. DOI: 10.1111/jopr.12105.

7. Elsaka SE, Hamouda IM, Swain MV. Titanium dioxide nanoparticles addition to a conventional glass-ionomer restorative: influence on physical and antibacterial properties. J Dent 2011;39(9):589-598. DOI: 10.1016/j.jdent.2011.05.006.

8. Ahmed MA, El-Shennawy M, Althomali YM, et al. Effect of titanium dioxide nano particles incorporation on mechanical and physical properties on two different types of acrylic resin denture base. World J Nano Sci Eng 2016;6(3):111-119. DOI: 10.4236/wjnse.2016.63011.

9. Hamouda IM, Beyari MM. Addition of glass fibers and titanium dioxide nanoparticles to the acrylic resin denture base material: comparative study with the conventional and high impact types. Oral Health Dent Manag 2014;13(1):107-112. DOI: 10.4172/2247-2452.1000553.

10. Harini P, Mohamed K, Padmanabhan TV. Effect of titanium dioxide nanoparticles on the flexural strength of polymethylmethacrylate: an in vitro study. Indian J Dent Res 2014;25(4):459-463. DOI: 10.4103/0970-9290.142531.

11. Alwan SA, Alameer SS. The effect of the addition of silanized nano titania fillers on some physical and mechanical properties of heat cured acrylic denture base materials. J Baghdad Coll Dent 2015;27(1):1-2. DOI: 10.0001/639.

12. Somani $M$, Khandelwal $M$, Punia $V$, et al. The effect of incorporating various reinforcement materials on flexural strength and impact strength of polymethylmethacrylate: a meta-analysis. J Indian Prosthod Soc 2019;19(2):101. DOI: 10.4103/jips.jips_313_18.

13. Wang W, Liao S, Zhu Y, et al. Recent applications of nanomaterials in prosthodontics.J Nanomater 2015;2015. p. 11.DOI: 10.1155/2015/408643.

14. Moudhaffar M, Ihab NS. Evaluation the effect of modified nano-fillers addition on some properties of heat cured acrylic denture base material. J Baghdad Coll Dent 2011;23:23-29.

15. Viswambharan $P$, Adhershitha AR. Effect of titanium oxide and zirconium oxide nanoparticle incorporation on the flexural strength of heat-activated polymethyl methacrylate denture base resins - an in vitro experimental study. Int J Prev Clin Dent Res 2020;7(4):91-95. DOI: 10.4103/ijpcdr.ijpcdr_49_20.

16. Heravi F, Ramezani M, Poosti M, et al. In vitro cytotoxicity assessment of an orthodontic composite containing titanium-dioxide nanoparticles. J Dent Res Dent Clin Dent Prospect 2013;7(4):192-198. DOI: 10.5681/joddd.2013.031.

17. Tsuji M, Ueda T, Sawaki K, et al. Biocompatibility of a titanium dioxidecoating method for denture base acrylic resin. Gerodontology 2016;33(4):539-544. DOI: 10.1111/ger.12204. 